\title{
EVALUATION OF HOST TESTING BY COMPARING INGESTION AND SETTLING BEHAVIOURS
}

\author{
W.R.M. SANDANAYAKA and N.E.M. PAGE-WEIR
}

\author{
The New Zealand Institute for Plant \& Food Research Limited, Mt. Albert \\ Research Centre, Private Bag 92-169, Auckland 1142, New Zealand
}

Corresponding author: msandanayaka@hortresearch.co.nz

\begin{abstract}
The electrical penetration graph (EPG) technique is being developed for rapid assessment of host range of potential xylem feeding invaders in New Zealand. Stylet penetration behaviours of adult spittle bug Carystoterpa fingens were monitored for $12 \mathrm{~h}$ on grape, lemon, apple and kiwifruit plants using EPG. A multiple-choice test of all four plant species was conducted concurrently with the EPG tests for comparison. In EPG tests the longest probing and ingestion periods were recorded on grape and lemon, while the shortest probing and ingestion periods were recorded on apple. Results for kiwifruit were intermediate and not significantly different from the other plant types. In the multiple-choice tests, more insects were found on grape and lemon than on apple and kiwifruit. The similar ranking of the host plants in both multiple-choice and EPG tests suggests that EPG is a valid tool for rapidly assessing host feeding acceptance and preference. Keywords: electrical penetration graph, Carystoterpa fingens, xylem feeding, host testing.
\end{abstract}

\section{INTRODUCTION}

Testing the potential host range of invasive insects is important for risk assessment and management before their establishment (Kirichenko et al. 2008; Kenis et al. 2009). The potential host-plant range of insects is commonly tested by measuring behaviours such as foraging (Schuler et al. 2003), settling (Prado \& Tjallingii 2007), feeding (Troncoso et al. 2005) and oviposition (Smith \& Capinera 2005; van den Berg et al. 2006). Miller \& Strickler (1984) defined a host plant as a plant that provides sensory cues, such as visual, olfactory, gustatory and tactile cues, to which the insect responds positively at each phase of the host-finding and acceptance process. Host specificity of insects is preferably assessed by both choice and no-choice tests (Withers 1997; Kirker et al. 2008), and the choice tests are used to test host-plant preference of insects (Smith \& Capinera 2005; van den Berg et al. 2006). Host acceptance behaviour is a key character responsible for host-plant specialisation of phytophagous arthropods (Skoracka et al. 2007).

The electrical penetration graph (EPG) technique has been applied to test the acceptance of plants for feeding by hemipterans (Calatayud et al. 1994; Powell 2000; Sandanayaka \& Backus 2008), and allows the quantification of stylet penetration activities and real feeding (ingestion) of the insect (Sandanayaka et al. 2007). EPG is designed to monitor the stylet penetration behaviour of individual insects on individual plants where the insects are not given a choice of more than one plant. In multiple-choice tests insects are allowed to choose one plant over the other according to their preferences.

This paper describes one of the host-range testing studies that has been carried out on the spittle bug Carystoterpa fingens Walker (Hemiptera: Aphrophoridae), an exotic xylem-feeding insect in New Zealand. The primary aim of these studies is to develop a rapid technique for host-range testing of any invading xylem feeder. This tool would be important for surveillance and management after their establishment. In this study, the acceptance of $C$. fingens on four selected plant species was monitored using EPG to measure the real feeding time, while multiple-choice tests were conducted to assess the foraging and settling behaviour of $C$. fingens on those plant species. 


\section{MATERIALS AND METHODS}

\section{Insects and plants}

Carystoterpa fingens adults of uncertain age were collected from Coprosma robusta M. Raoul. 'Karamu' plants in Mount Albert, Auckland, during the months of OctoberDecember 2008. Insects were collected in the morning every Sunday-Thursday and maintained on fresh $C$. robusta shoots (stems were placed in water) in cages in the laboratory at $19 \pm 1^{\circ} \mathrm{C}, 60 \%$ relative humidity and $16: 8 \mathrm{~h}$ light:dark. The laboratory was illuminated with florescent light bulbs that distributed light evenly into the choicetest cages and the EPG experimental setup. Insects were maintained for $24 \mathrm{~h}$ in these conditions before testing, to allow adjustment to the laboratory environment.

Three plants that are not recorded as hosts of $C$. fingens, apple (Malus domestica Borkh.) 'Golden Delicious x Braeburn', kiwifruit (Actinidia deliciosa C. F. Liang et A. R. Ferguson) 'Hort16A' and lemon (Citrus limon Burm. f.) 'Meyer', were selected for the tests. Grape (Vitis vinifera L.) 'Cabernet Sauvignon' was used as the control, as feeding acceptance by $C$. fingens has been reported in a previous study (Sandanayaka 2008). The growth and size of the plants varied slightly between species. Apple plants were smaller than the other plants and lemon plants had the most new growth. All of these plants were grown in pots in a glasshouse under similar light and temperature regimes and had not been treated with insecticides for 4 weeks before experimentation.

\section{Choice test}

The multiple-choice tests were performed, under the same laboratory conditions as described above, in a fine nylon gauze cage $(88 \times 88 \times 60 \mathrm{~cm})$. One plant each of apple, grape, kiwifruit and lemon were placed at each corner of the test cage on the night before the experiment. Two identical cages were set up, which enabled two replicates to be performed each day, repeated six times, making a total of 12 replicates. Fresh plants and insects were used for each replicate. In the morning, between 0800 and 0830, eight adult $C$. fingens (a mixture of 50:50 females:males) were released into the centre of the cage. Observations of the number of insects on each plant, and the number remaining on the sides of the cage, were recorded at hourly intervals for $10 \mathrm{~h}$. Plant species were rotated anti-clockwise within the cage for each replicate.

The median difference of insects on each plant species at each hour were analysed by Wilcoxon Rank Sum Test.

\section{EPG test}

A mixture of 50:50 female:male adult $C$. fingens was used for the EPG tests. The protocol described below was used for wiring all insects. Insects were immobilized for wiring by holding them at $-20^{\circ} \mathrm{C}$ for $2-3 \mathrm{~min}$. A loop made at the edge of a $20-\mu \mathrm{m}$ gauge gold wire (3-4 cm long) was dipped in silver conducting paint with n-butyl acetate solvent (Ladd Research Industries, Burlington, VT, USA) and attached to the dorsum of the insect, avoiding the wings. The other end of the gold wire was attached to a 4-cm long copper wire, which was connected to a copper nail inserted into the amplifier of EPG Giga 4 monitor. Wired insects were allowed to recover and acclimatise to the gold wire tether on a $C$. robusta shoot for 10-15 min before being connected to the amplifier.

The plant species were randomly assigned to four channels of the EPG monitor. EPG signal recording started with a non-probing baseline while insects were being placed in holders and readied for recording. Insects were then lowered onto the plants, one at a time, according to the numerical order of the channels. Insects were placed onto the young shoots of the plants, in the preferred location for feeding that was observed in the choice tests above. The stylet penetration behaviour of the insects was recorded for $12 \mathrm{~h}$, using WinDaq Pro+ software (DATAQ instruments, Ohio, USA) and data were saved as WinDaq files for waveform measurements and analysis. Thirteen replicates were carried out. Insects that escaped from the wire before completion of $6 \mathrm{~h}$ of recordings were discarded.

Individual recordings ranged from $8-12 \mathrm{~h}$, as seven insects escaped from the wire after $8 \mathrm{~h}$ of recording. EPG data were analysed in two separate blocks: 6 and $12 \mathrm{~h}$. EPG waveforms recorded from the insects that continued for the first $6 \mathrm{~h}$ (apple: $\mathrm{n}=10$; grape: 
$\mathrm{n}=13$; kiwifruit: $\mathrm{n}=11$ and lemon: $\mathrm{n}=13$ ) were analysed separately from the waveforms recorded from the insects that continued for $12 \mathrm{~h}$ (apple: $\mathrm{n}=9$; grape: $\mathrm{n}=11$; kiwifruit: $\mathrm{n}=10$ and lemon: $\mathrm{n}=10$ ).

The main EPG waveform parameters that relate to xylem ingestion, $\mathrm{C}$ (regular waveforms representing ingestion), D2 (interruptions between $\mathrm{C}$ waveforms) and CO (C waveforms between straight lines), as described in Sandanayaka et al. (2007) were measured. Durations of waveform parameters relating to xylem ingestion and the total non-probing period were analysed using analysis of variance (ANOVA), and plant species means were separated by Tukey's Least Significant Difference Test.

\section{Choice test}

\section{RESULTS}

Nearly $50 \%$ of the adult $C$. fingens had settled on the plants within $1 \mathrm{~h}$ of being released into the cages. The number of insects remaining on the sides of the cage consistently decreased during the test, while the number of insects settling on grape and lemon increased over time. The number of insects found on kiwifruit increased during the first $3 \mathrm{~h}$ followed by a gradual decrease over the last $6 \mathrm{~h}$ of observations. A similar number of insects were found on apple and kiwifruit at the end of the 10-h observation period. More insects were located on lemon plants than on apple plants during each of the observation periods (Table 1 ) and these plants consistently ranked as significantly different $(\mathrm{P}<0.05)$.

TABLE 1: The average number of Carystoterpa fingens adults settled on each plant in the multiple-choice test during the $10 \mathrm{~h}$ observation.

\begin{tabular}{lllll}
\hline Time $(\mathrm{h})$ & Grape & Lemon & Apple & Kiwifruit \\
\hline 1 & $1.16 \mathrm{ab}^{1}$ & $1.75 \mathrm{a}$ & $0.25 \mathrm{~b}$ & $0.66 \mathrm{~b}$ \\
2 & $1.16 \mathrm{~b}$ & $2.08 \mathrm{a}$ & $0.83 \mathrm{~b}$ & $1.08 \mathrm{~b}$ \\
3 & $1.58 \mathrm{a}$ & $2.00 \mathrm{a}$ & $0.91 \mathrm{~b}$ & $1.33 \mathrm{ab}$ \\
4 & $1.75 \mathrm{~b}$ & $2.41 \mathrm{a}$ & $0.83 \mathrm{c}$ & $1.33 \mathrm{bc}$ \\
5 & $1.91 \mathrm{~b}$ & $2.58 \mathrm{a}$ & $0.83 \mathrm{c}$ & $1.25 \mathrm{bc}$ \\
6 & $2.08 \mathrm{a}$ & $2.66 \mathrm{a}$ & $0.91 \mathrm{~b}$ & $1.25 \mathrm{~b}$ \\
7 & $2.25 \mathrm{a}$ & $2.66 \mathrm{a}$ & $0.91 \mathrm{~b}$ & $1.16 \mathrm{~b}$ \\
8 & $2.25 \mathrm{a}$ & $2.66 \mathrm{a}$ & $0.91 \mathrm{~b}$ & $1.16 \mathrm{~b}$ \\
9 & $2.50 \mathrm{a}$ & $2.75 \mathrm{a}$ & $1.08 \mathrm{~b}$ & $1.08 \mathrm{~b}$ \\
10 & $2.50 \mathrm{a}$ & $2.66 \mathrm{a}$ & $1.08 \mathrm{~b}$ & $1.08 \mathrm{~b}$
\end{tabular}

${ }^{1}$ Values that share the same letters indicate that the means were not statistically different at that time (Wilcoxon Rank Sum test, $\mathrm{P}<0.05$ ).

\section{EPG test}

EPG waveforms recorded in both the 6- and 12-h data periods showed both probing and xylem ingestion activities. In both periods, the longest duration for non-probing (Np) was consistently recorded on apple (Table 2). The shortest non-probing duration was recorded on grape, but this was not significantly different from kiwifruit or lemon $(\mathrm{P}<0.05)$. However the 12-h periods indicated that the length of time insects spent probing kiwifruit was not significantly different from apple.

The shortest xylem ingesting duration (C) was recorded on apple in both the 6- and 12 -h periods. The duration of xylem ingestion for insects on kiwifruit was not significantly different from apple during the 12-h period. However, the high level of acceptance in grape and lemon for feeding by $C$. fingens remained the same in both the 6-h and 12-h periods (Table 2). 
TABLE 2: $\quad$ Mean $\pm \mathrm{SE}$ durations ( $\mathrm{min}$ ) of stylet penetration activities, non-probing (Np), xylem ingestion (C), interruptions between ingestion (D2) and all the waveforms relating to ingestion $(\mathrm{C}+\mathrm{CO}+\mathrm{D} 2)$, of Carystoterpa fingens on four plant species over 6- and 12-h monitoring periods.

\begin{tabular}{lcccc}
\hline EPG parameters & Grape & Lemon & Apple & Kiwifruit \\
\hline $6 \mathrm{~h}$ monitoring & & & & \\
No. of insects & 13 & 13 & 10 & 11 \\
$\mathrm{~Np}$ & $49.5 \pm 12.3 \mathrm{~b}^{1}$ & $61.7 \pm 18.3 \mathrm{~b}$ & $223 \pm 27.2 \mathrm{a}$ & $73.8 \pm 21.0 \mathrm{~b}$ \\
$\mathrm{C}$ & $271 \pm 24.1 \mathrm{~b}$ & $255 \pm 17.6 \mathrm{~b}$ & $77.5 \pm 27.9 \mathrm{a}$ & $225 \pm 25.5 \mathrm{~b}$ \\
$\mathrm{D} 2$ & $3.9 \pm 0.6 \mathrm{a}$ & $3.5 \pm 0.5 \mathrm{a}$ & $3.5 \pm 1.0 \mathrm{a}$ & $5.0 \pm 0.8 \mathrm{a}$ \\
All C & $276 \pm 23.8 \mathrm{~b}$ & $259 \pm 17.9 \mathrm{~b}$ & $88.5 \pm 27.9 \mathrm{a}$ & $245 \pm 24.8 \mathrm{~b}$ \\
\hline $12 \mathrm{~h}$ monitoring & & & 9 & 10 \\
No. of insects & 11 & 10 & & \\
Np & $122 \pm 29.5 \mathrm{~b}$ & $158 \pm 54.3 \mathrm{~b}$ & $398 \pm 69.1 \mathrm{a}$ & $212 \pm 53.1 \mathrm{ab}$ \\
$\mathrm{C}$ & $555 \pm 37.2 \mathrm{~b}$ & $501 \pm 52.0 \mathrm{~b}$ & $211 \pm 65.8 \mathrm{a}$ & $404 \pm 57.6 \mathrm{ab}$ \\
D2 & $5.8 \pm 0.5 \mathrm{a}$ & $7.2 \pm 0.9 \mathrm{a}$ & $6.2 \pm 1.4 \mathrm{a}$ & $7.2 \pm 0.9 \mathrm{a}$ \\
All C & $563 \pm 36.4 \mathrm{~b}$ & $512 \pm 53.2 \mathrm{~b}$ & $227 \pm 63.8 \mathrm{a}$ & $441 \pm 53.5 \mathrm{~b}$ \\
\hline
\end{tabular}

${ }^{1}$ Mean values followed by different letters in each row are significantly different - Tukey's LSD, $\mathrm{P}<0.05$.

\section{DISCUSSION}

The host preference and feeding acceptance of $C$. fingens revealed from the multiplechoice and EPG tests, respectively, produced similar rankings for the plant species tested. In the multiple-choice tests, the insects could freely move to and settle on the plants that were most attractive to them. In EPG experiments, each individual was attached to a 3-4 cm long wire that allowed movement only in a limited area upon the test plant. Despite this movement restriction, every insect tested showed stylet penetration activities and attempted feeding on the test plants. The length of time individual insects probed into plants and spent ingesting xylem contents varied between plants according to how acceptable they were for feeding. Accordingly, the results revealed that lemon and grape were more acceptable than kiwifruit and apple for $C$. fingens.

Plant preference in this study was estimated by observing the foraging and settlement behaviours of $C$. fingens. The data from choice experiments indicated that adults preferred both lemon and grape significantly more than apple and kiwifruit. Insects that were released into cages took some time to settle on their preferred host plants. The insects in the cages were mobile and active and moved among plants until they settled at feeding sites. The average number of insects on lemon plants was always higher than on any other plants. The new foliage on lemon plants could have been a strong attractant to the insects, resulting in the high levels of preference from the first hour of observation. In contrast, apple plants were the smallest in size among all four of the plant types tested and had the lowest number of insects in the multiple-choice tests. The differences in growth and sizes of the plants were not of concern for these first multiple-choice tests as the aim of this study was comparing the ranking produced by the two techniques. The difference in preference between kiwifruit and grape was not so obvious, but the average number of insects gradually increased on grape and decreased on kiwifruit, suggesting that grape is ranked more preferred than kiwifruit.

The consistently lower preference that $C$. fingens expressed for apple in the multiple choice test was reflected in the real feeding time recorded using the EPG technique. Although the insects were not given a choice in the EPG experiments, durations of ingesting xylem were consistently the lowest on apple compared to the other plants. Probing is a crucial activity in host-plant selection after an insect has landed on a plant. EPG data provide a picture of when the insects probe and the stylet pathway during 
probing. Detailed understanding of stylet penetration activities via EPG has been used to answer a number of research questions about hemipteran feeding (Calatayud et al. 1994; Sandanayaka \& Backus 2008).

In this study, a mixture of males and females was tested to minimise variability, as female choice may be linked with ovipositional preferences. Only the foraging, settling and feeding behaviours of $C$. fingens were considered, to focus on host plant preference and acceptance. However, no differences in the behaviours of males and females were observed in this study.

By analysing EPG data in two time periods (6 and $12 \mathrm{~h}$ ) a better overview of the feeding behaviour of $C$. fingens was obtained. The 6-h long EPG data showed significant differences in feeding on apple and kiwifruit but this changed over time and no significant difference was found by the conclusion of the $12 \mathrm{~h}$ period. Although the comparisons between the EPG data and the behaviour of $C$. fingens in the multiple-choice tests are indirect, there was also no difference in the number of insects on kiwifruit and on apple at the end of the 10-h period in the multiple-choice tests.

This study has shown EPG to be a useful tool for developing a rapid technique for screening the host range of xylem feeding insects. EPG monitoring of real time stylet penetration activities of $C$. fingens, produced more detailed information of the feeding behaviour on different plants than was revealed by settling behaviour in the multiplechoice tests. However, both methods consistently revealed that lemon and grape are preferred and accepted for feeding by $C$. fingens, relative to kiwifruit and apple, and that this ranking of the host plants was consistent between the two assay types.

\section{ACKNOWLEDGEMENTS}

Sincere thanks to Joanne Poulton and John Charles for their valuable comments on this paper, and to Alison Duffy and Chandrasiri Ranatunga for providing plants for this study. This research was funded by New Zealand's Foundation for Research, Science and Technology through the Better Border Biosecurity B3 Programme (www.b3nz.org).

\section{REFERENCES}

Calatayud PA, Rahbe Y, Tjallingii WF, Tertuliano M, Ru BL 1994. Electrically recorded feeding behaviour of cassava mealybug on host and non-host plants. Entomologia Experimentalis Applicata 72: 219-232.

Kenis M, Auger-Rozenberg MA, Roques A, Timms L, Pere C, Cock M, Settele J, Augustin S, Lopez-Vaamonde C 2009. Ecological effects of invasive alien insects. Biological Invasions 11: 21-45.

Kirichenko N, Baranchikov Y, Gregoire J, Flament, J, Kenis, M 2008. Ranking of the potential host plants for the invasive Siberian moth in Europe. Proceedings of the $23^{\text {rd }}$ International Congress of Entomology, Durban, South Africa. CD Abstract No. 0782.

Kirker GT, Sampson BJ, Pounders CT, Spiers JM, Boyd DW 2008. The effects of stomatal size on feeding preference of Azalea Lace Bug, Stephanitis pyrioides Hemiptera: Tingidae, on selected cultivars of Evergreen Azalea. Hortscience 43: 2098-2103.

Miller JR, Strickler KL 1984. Finding and accepting host plants. In: Bell WJ, Cardé RT ed. Chemical Ecology of Insects. Chapman \& Hall, London, U.K. Pp. 127-157.

Powell GHJ 2000. Host-selection behaviour by genetically identical aphids with different plant preferences. Physiological Entomology 25: 54-62.

Prado E, Tjallingii W 2007. Behavioral evidence for local reduction of aphid-induced resistance. Journal of Insect Science 7 (48): available online at http://www. insectscience.org/7.48.

Sandanayaka M 2008. Using EPG to compare acceptance by the spittle bug Carystoterpa fingens of four plant species. Proceedings of the $23^{\text {rd }}$ International Congress of Entomology, Durban, South Africa. CD Abstract No 443. 
Sandanayaka WRM, Backus EA 2008. Quantitative comparison of stylet penetration behaviors of Glassy winged Sharpshooter, Homalodisca vitripennis on selected hosts. Journal of Economic Entomology 101: 1183-1197.

Sandanayaka WRM, Chhagan A, Ramankutty P 2007. Host plant testing of the spittle bug Carystoterpa fingens by stylet penetration behaviour. New Zealand Plant Protection 60: 78-84.

Schuler TH, Potting RPJ, Denholm I, Clark SJ, Clark AJ, Stewart CN, Poppy GM 2003. Tritrophic choice experiments with Bt plants, the diamondback moth Plutella xylostella and the parasitoid Cotesia plutellae. Journal of Insect Behavior 12: 351-361.

Skoracka A, Kuczynski L, Rector BG 2007. Divergent host acceptance behavior suggests host specialization in populations of the polyphagous mite Abacarus hystrix Acari: Prostigmata : Eriophyidae. Environmental Entomology 36: 899-909.

Smith TR, Capinera JL 2005. Host preferences and habitat associations of some Florida grasshoppers Orthoptera : Acrididae. Environmental Entomology 34: 210-224.

Troncoso AJ, Vargas RR, Tapia DH, Olivares-Donoso R, Niemeyer HM 2005. Host selection by the generalist aphid Myzus persicae Hemiptera: Aphididae and its subspecies specialized on tobacco, after being reared on the same host. Bulletin of Entomological Research 95: 23-28.

Van den Berg J, de Bruyn AJM, van Hamburg H 2006. Oviposition preference and survival of the maize stem borer, Busseola fusca Lepidoptera : Noctuidae, on Napier grasses, Pennisetum spp., and maize. African Entomology 14: 211-218.

Withers TM 1997. Changes in plant attack over time in no-choice tests: An indicator of specificity. Proceedings of the 50th New Zealand Plant Protection Conference: 214-217. 